American Journal of Environmental Sciences 4 (4): 367-372, 2008

ISSN 1553-345X

(C) 2008 Science Publications

\title{
Comparison of Twelve Dielectric Moisture Probes for Soil Water Measurement under Saline Conditions
}

\author{
M. Inoue, B.A. Ould Ahmed, T. Saito and M. Irshad \\ Arid Land Research Center, Tottori University, 1390 Hamasaka, Tottori 680-0001, Japan
}

\begin{abstract}
Recently the research on the determination of soil water content and electrical conductivity using automated technique has received tremendous attention. Selecting the type of system that should be used for soil water measurement under saline conditions depends on its precision. A laboratory study was carried out to measure the soil water content $(\theta)$ and soil solution electrical conductivity $\left(\mathrm{EC}_{\mathrm{w}}\right)$ using eight portable dielectric moisture probes namely ML1, ML2, MP4, WET, SK8, MIN, EC2 and SM2 and four profile probes namely ES, AG, P1 and P2. Air-dried Tottori sand dune soil was converted into saline by $\mathrm{NaCl}$ solutions of various concentrations. The out-put results of moisture probes showed that measurement accuracy was strongly dependent on the concentration of salt in the soil. Among the sensors WET, EC2 and ES exhibited higher sensitivity to the salts and over estimated water content by $0.04-0.08 \mathrm{~cm}^{3} \mathrm{~cm}^{-3}$ whereas MP4, WET, SM2, ES, AG and P1 sensors also over estimated the volumetric water content by $0.02-0.03 \mathrm{~cm}^{3} \mathrm{~cm}^{-3}$ at $3.83 \mathrm{dS} \mathrm{m}^{-1}$ soil salinity as compared to normal soil. Higher $\mathrm{EC}_{\mathrm{w}}$ increased the relative error of soil water measurement across the sensors. Among the moisture meters, commercially available ML1, ML2, SK8 and P2 gave sufficient accuracy in the presence of salts.
\end{abstract}

Key words: Dielectric moisture probe, saline soil, electrical conductivity, water content, dry land

\section{INTRODUCTION}

Salinity is one of the major environmental problems confronting agriculture especially in arid and semi-arid regions ${ }^{[25]}$. The accumulation of high soluble salts in the soil can significantly decrease the value and productivity of agricultural lands. Over-irrigation has exacerbated the prevailing situation. It is necessary to prevent soil deterioration through proper management of water. Rehabilitating salt affected soils remains time and labor intensive and economically not viable. Fundamental knowledge on soil water content and salt accumulation are important for the sustainability of agriculture. Mwale et al. ${ }^{[17]}$ reported that accurate measurement of soil moisture content is crucial for studies that aim to understand crop response to water stress and is important for practical applications such as irrigation scheduling. Rapid and reliable techniques for monitoring in situ volumetric soil water content and electrical conductivity of soils is necessary for the prevention of soil salinization. Soil water contents are measured in the field using gravimetric methods, neuron scattering, or techniques based upon the thermal or electrical properties of soil-air-water mixtures. The studies of soil-water distribution at small spatial scale are limited by the lack of suitable measurement techniques ${ }^{[1]}$. Time-domain reflectometry (TDR) method, frequency domain reflectometry (FDR) method and the amplitude-domain reflectometry (ADR) method are the current available methods for the electrical measurements of the dielectric constant. Electrical methods are advantageous because they are automated to measure soil water and salinity at multiple locations. Topp and Davis ${ }^{[26]}$ reported the TDR measurement of soil water content as well-accepted method. With knowledge of the electrical properties of soil-air-water mixtures and appropriate experimental calibrations, the bulk soil dielectric permittivity can be related to the volumetric water content and the bulk soil electrical conductivity can be related to the soil water electrical conductance. The variables which affect the electrical response in soils are texture, structure, soluble salts, water content, temperature, density and measurement frequency ${ }^{[27]}$.

The theoretical background for the use of TDR was well explained by various authors ${ }^{[27,9,23,12]}$. Briefly the TDR determines the dielectric constant $\left(\mathrm{K}_{\mathrm{d}}\right)$ by measuring the propagation time of electromagnetic waves, sent from a pulse generator of a cable tester immersed in a medium. Capacitive dielectric sensors

Corresponding Author: Inoue Mitsuhiro, Arid Land Research Center, Tottori University, 1390 Hamasaka, Tottori 680-0001, Japan Tel: +81-857-23-3411 Fax: +81-857-29-6199 
are a low-disturbance technique, inexpensive and nonhazardous, that provides instantaneous readings of volumetric water content, $\theta\left(\mathrm{m}^{3} \mathrm{~m}^{-3}\right)$. As a result, some capacitance sensors have become an alternative to the more expensive TDR technique ${ }^{[5,4,10,19,22,16]}$. Capacitive sensor reading may strongly depend on the electric field frequency used by the system ${ }^{[15]}$ and the electrical conductivity of the material ${ }^{[3,24]}$. Both TDR and capacitance methods depend on changes in the soil dielectric constant to measure soil volumetric water content. Therefore, ease of use and other factors affecting the output of the instruments (e.g., temperature, salinity) become considerations in the choice of methods ${ }^{[29,18]}$.

The concurrent measurement of both water content and electrical conductivity provide new research and management options. Moisture sensors based on dielectric properties are powerful tool for real-time, simultaneous measurement of soil water content and bulk electrical conductivity on the same in situ soil sample. However, the problems arise with the technique in soils with significant salts as reported by Topp et al. ${ }^{[28]}$. Relatively less attention has been given to the application of these automated techniques to the highly saline soils. The effects of high magnitude of salts in the soils on the simultaneous measurement of volumetric water content $(\theta)$ and soil salinity using dielectric moisture probes are not fully investigated. Therefore the current study was aimed to test the dielectric moisture probes on the precise simultaneous determination of $\theta$ in saline sandy soil.

\section{MATERIALS AND METHODS}

During this study the measurement of soil water content and soil solution electrical conductivity was carried out using various dielectric moisture probes at Arid Land Research Center Tottori University Japan. Eight types of portable dielectric moisture probes namely ML1, ML2, MP4, WET, SK8, MIN, EC2 and SM2 and four profile probes namely ES, AG, P1 and P2 were used for the determination of volumetric water content $(\theta)$ and soil solution electrical conductivity $\left(\mathrm{EC}_{\mathrm{w}}\right)$. These moisture probes are classified into three methods on the basis of measuring mechanisms: (i) EC2, ES and AG probes are principally based on capacitance method, (ii) SK8 and MIN sensors are based on time-domain reflectometry (TDR) method ${ }^{[8]}$, (iii) WET sensor is based on frequency domain reflectometry (FDR) method and (iv) ML1, ML2, MP4, SM2, P1 and P2 probes are based on amplitude-domain reflectometry (ADR) method. The TDR, FDR and ADR are also known as Dielectric method. Dalton and van
Table 1: Some physical properties of the dune sand soil

\begin{tabular}{ll}
\hline Value & Property \\
\hline 96.1 & Sand (\%) \\
0.4 & Silt $(\%)$ \\
3.5 & Clay $(\%)$ \\
2.66 & Particle density $\rho_{\mathrm{s}}\left(\mathrm{gm}^{-3}\right)$ \\
0.08 & Field capacity, FC $\left(\mathrm{cm}^{3} \mathrm{~cm}^{-3}\right)$ \\
0.024 & Wilting point WP $\left(\mathrm{cm}^{3} \mathrm{~cm}^{-3}\right)$ \\
0.02 & Sat saturated hydraulic conductivity Ks $\left(\mathrm{cm} \mathrm{s}^{-1}\right)$ \\
1.55 & Bulk density $\rho_{\mathrm{b}}\left(\mathrm{g} \mathrm{cm}^{-3}\right)$ \\
0.413 & Saturated soil moisture content $\left(\mathrm{cm}^{3} \mathrm{~cm}^{-3}\right)$ \\
\hline
\end{tabular}

Genuchten $^{[6]}$ reported that the commercially available TDR probe with rod length of $30 \mathrm{~cm}$ failed to provide accurate measurements of $\theta$ when the salt concentration was higher. During this study, the TDR (SK8) custom made probe was modified by a rod length of $6 \mathrm{~cm}$ and tested for its output accuracy in higher saline soil.

Saline solutions were prepared with the addition of sodium chloride $(\mathrm{NaCl})$ salt at the rate of $0.05,1,2,3.5$, $5,10,20,30$ and $50 \mathrm{~g} \mathrm{~L}^{-1}$ to achieve the $\mathrm{EC}_{\mathrm{w}}$ levels of water as 1.01, 2.0, 3.83, 6.52, 9.15, 17.7, 34.1, 48.2, $74.7 \mathrm{dS} \mathrm{m}^{-1}$. Tottori sand dune soil was used in the experiment. The physical properties of the soil are given in Table 1. The soil was air-dried, sieved ( $<2 \mathrm{~mm})$ and calibrated with these saline solutions by thoroughly mixing in $2 \mathrm{~L}$ vinyl bags. The volumetric soil water contents $(\theta)$ attained in the respective saltsoil treatments were: $0.0155,0.031,0.0465,0.062$, $0.093,0.124,0.155,0.186$ and $0.248 \mathrm{~cm}^{3} \mathrm{~cm}^{-3}$ respectively. The saturated volumetric water contents were calculated from the given mass of the dry soil to the mass of water. The salinized samples of soil were packed uniformly in the known volume of container and left at room temperature before reading to diminish the possible temperature effect. The portable sensors were inserted into a container packed with known volume of sand whereas the profile probes were immersed into a purpose-built access tube set in the center of the container ${ }^{[13]}$. The output readings were recorded and the measuring accuracy of the probes was compared for the soil water content in fresh water as well as saline soil solution. Water content was determined by gravimetric simultaneously with dielectric moisture probe readings.

\section{RESULTS AND DISCUSSION}

The experiment demonstrated that output reading of the commercially available dielectric moisture probes was profoundly affected by the salinity level of the sandy soil. The conclusive data of the soil water measured by the moisture probes are given in Fig. 1 and 2.

The relationship between output voltage $(\mathrm{x})$ and volumetric water content $(\theta)$ for ML1 probe was also affected by the saline conditions. It was observed that at the output voltage of 0.4 , the volumetric water contents 
Am. J. Environ. Sci., 4 (4): 367-372, 2008
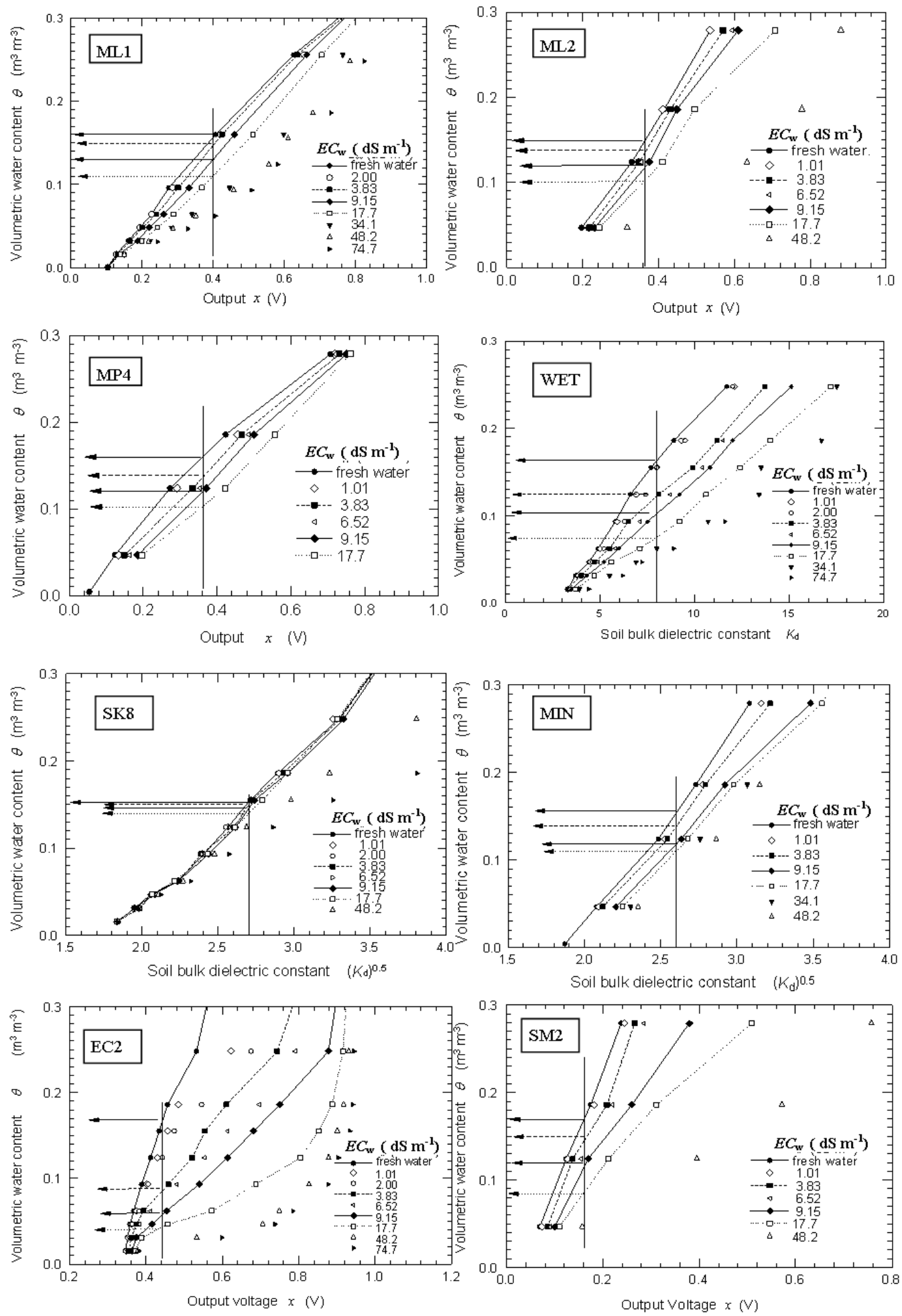

Fig. 1: Calibration of profile dielectric moisture probes 

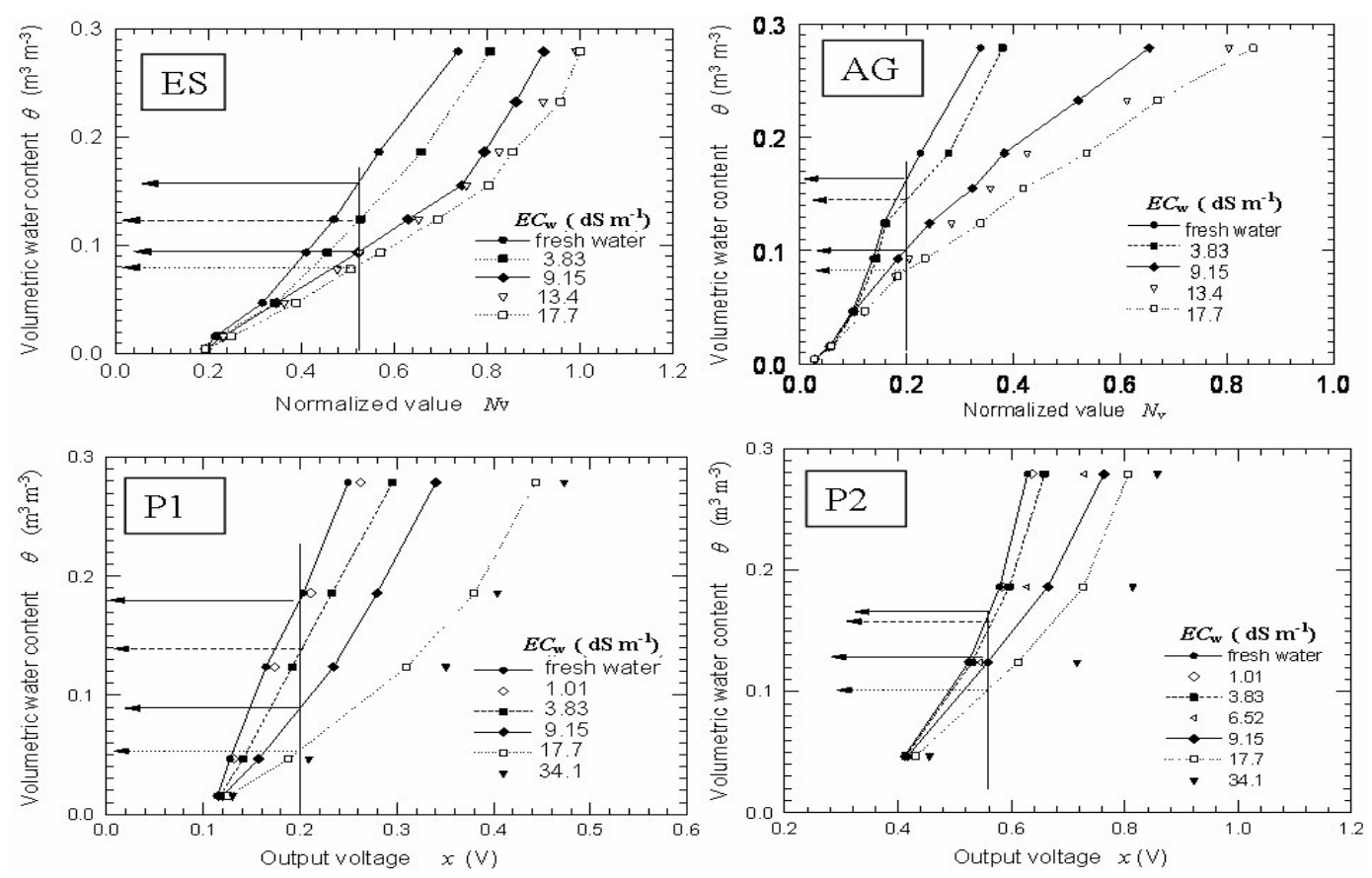

Fig. 2: Calibration of profile probes

$\left(\mathrm{m}^{3} \mathrm{~cm}^{-3}\right)$ were noted as 0.16 for fresh water, 0.15 for soil solution of $3.83 \mathrm{dS} \mathrm{m}^{-1}$ and 0.13 for soil solution of $9.15 \mathrm{dS} \mathrm{m}^{-1}$. Thus an overestimation of 0.01 and 0.03 $\mathrm{cm}^{3} \mathrm{~cm}^{-3}$ for $\theta$ was noted for fresh water as compared to the salinity of 3.83 and $9.15 \mathrm{dS} \mathrm{m}^{-1}$ respectively with ML1.

The commercially available WET sensor has three rods with length of $6.8 \mathrm{~cm}$ and $0.3 \mathrm{~cm}$ diameter. It measures the dielectric constant $\left(\mathrm{K}_{\mathrm{d}}\right), \mathrm{ECa}$ and temperature simultaneously. WET sensor is based on FDR method and provides useful information concerning water status in soils ${ }^{[21]}$. The WET sensor exhibited an exceeded value of $0.04 \mathrm{~cm}^{3} \mathrm{~cm}^{-3}$ for fresh water at $K_{d}$ value of 8 as compared to $3.83 \mathrm{dS} \mathrm{m}^{-1}$ soil water. The accuracy of WET sensor for low water content $\quad(<0.01)$ could not be guaranteed. Regalado et $a l .{ }^{[20]}$ found that the WET sensor measurement was not accurate when saline solution increased above $3 \mathrm{dS} \mathrm{m}^{-1}$.

The study investigated the effects of $\mathrm{EC}_{\mathrm{w}}$ on the output values of soil bulk dielectric constant $\left(\mathrm{K}_{\mathrm{d}}\right)$ of SK8 and MIN probes. Generally these sensors are based on TDR method. The SK8 sensor is considered as less affected by the salts concentration, was tested in the saline soil solution of $17.7 \mathrm{dS} \mathrm{m}^{-1}$ for measuring its accuracy for $\theta$ in relation to $\mathrm{EC}_{\mathrm{w}}$. In case of SK8 at output $\left(K_{d}\right)$ value of 2.7 , a similar $\theta$ was measured (i.e.,
$0.15 \mathrm{~cm}^{3} \mathrm{~cm}^{-3}$ ) for fresh water as well as for $3.83 \mathrm{dS}$ $\mathrm{m}^{-1}$ soil solution. The low disparity in the water content for highly saline soil solution may also show the lower effects of salts on the SK8 output. For MIN sensor, at $\mathrm{Kd}$ value of 2.6 the water contents were noted as $0.16 \mathrm{~cm}^{3} \mathrm{~cm}^{-3}$ for fresh water, $0.14 \mathrm{~cm}^{3} \mathrm{~cm}^{-3}$ for the salinity level of $3.83 \mathrm{dS} \mathrm{m}^{-1}$ and 0.12 for salinity level of $9.12 \mathrm{dS} \mathrm{m}^{-1}$.

Several researchers reported TDR as the reliable technique for the measurement of $\theta^{[27,2,11,12]}$. The use of TDR for the measurement of apparent bulk soil electrical conductivity was first demonstrated by the Dalton et al. ${ }^{[7]}$. Measurement of the EC using TDR is based on attenuation of the applied signal voltage as it traverses the medium of interest. As the traverse electromagnetic waves propagate along TDR probes buried in the soil, the signal energy is attenuated in proportion to the electrical conductivity along the travel path. This proportional reduction in signal voltage is accurately related to the bulk soil electrical conductivity ${ }^{[14]}$.

The EC2 sensor which is a capacitance type moisture meter can measure water content from absolute dry to saturated soils. Upon calibration, the $\theta$ value was noted as $0.17 \mathrm{~cm}^{3} \mathrm{~cm}^{-3}$ for fresh water at voltage of 0.44 representing an overestimation of 0.08 $\mathrm{cm}^{3} \mathrm{~cm}^{-3}$ than $0.09 \mathrm{~cm}^{3} \mathrm{~cm}^{-3}$ as for $3.83 \mathrm{dS} \mathrm{m}^{-1}$. 
Am. J. Environ. Sci., 4 (4): 367-372, 2008

Table 2: Effect of electrical conductivity (EC) on measurement of volumetric water content ()

\begin{tabular}{|c|c|c|c|c|c|c|}
\hline Symbol & Out & Output reading & FW & $\left.\mathrm{EC}(\mathrm{dS} \mathrm{m})^{-1}\right) 3.83$ & $\mathrm{EC}\left(\mathrm{dS} \mathrm{m}^{-1}\right) 9.15$ & $\left.\mathrm{EC}(\mathrm{dS} \mathrm{m})^{-1}\right) 17.7$ \\
\hline \multicolumn{7}{|c|}{ Potable probe } \\
\hline ML1 & $0-1(\mathrm{v})$ & $x=0.4$ & 0.16 & 0.15 & 0.13 & 0.11 \\
\hline ML2 & $0-1(\mathrm{v})$ & $x=0.36$ & 0.15 & 0.14 & 0.12 & 0.10 \\
\hline MP4 & $0-1(\mathrm{v})$ & $x=0.36$ & 0.16 & 0.14 & 0.12 & 0.10 \\
\hline WET & $\mathrm{k}_{\mathrm{d}} \mathrm{EC}_{\mathrm{a}} \mathrm{T}_{\mathrm{a}}$ & $\mathrm{K}_{\mathrm{d}}=8$ & 0.165 & 0.125 & 0.105 & 0.075 \\
\hline SK8 & $\mathrm{k}_{\mathrm{d}} \mathrm{EC}_{\mathrm{a}} \mathrm{T}_{\mathrm{a}}$ & $\left(\mathrm{K}_{\mathrm{d}}\right)^{0.5}=2.7$ & 0.155 & 0.150 & 0.145 & 0.14 \\
\hline MIN & $\mathrm{k}_{\mathrm{d}} \mathrm{EC}_{\mathrm{a}} \mathrm{T}_{\mathrm{a}}$ & $(\mathrm{Kd})^{0.5}=2.6$ & 0.16 & 0.14 & 0.12 & 0.11 \\
\hline EC2 & $0.25-1(\mathrm{v})$ & $x=0.44$ & 0.17 & 0.09 & 0.06 & 0.04 \\
\hline SM2 & $0-1(\mathrm{v})$ & $x=0.16$ & 0.17 & 0.15 & 0.12 & 0.085 \\
\hline \multicolumn{7}{|c|}{ Profile probe } \\
\hline ES & $\mathrm{F}(\mathrm{Hz})$ & $\mathrm{N}_{\mathrm{v}}=0.52$ & 0.16 & 0.125 & 0.10 & 0.08 \\
\hline AG & $\mathrm{F}(\mathrm{Hz})$ & $\mathrm{N}_{\mathrm{v}}=0.2$ & 0.165 & 0.145 & 0.10 & 0.08 \\
\hline P1 & $0-1(\mathrm{v})$ & $x=0.2$ & 0.18 & 0.14 & 0.09 & 0.055 \\
\hline P2 & $0-1(v)$ & $x=0.56$ & 0.17 & 0.16 & 0.13 & 0.10 \\
\hline
\end{tabular}

The calibration results for ES and AG probes are shown in Fig. 2. For ES sensor, the dimensionless parameter $\left(\mathrm{N}_{\mathrm{v}}\right)$ was determined by the following equation:

$$
\mathrm{N}_{\mathrm{v}}=\frac{\mathrm{F}-\mathrm{F}_{\mathrm{a}}}{\mathrm{F}_{\mathrm{w}}-\mathrm{F}_{\mathrm{a}}}
$$

where $F, F_{a}$ and $F_{w}$ denote the output values for the sample, air and water respectively. It was found that at $\mathrm{N}_{\mathrm{v}} 0.52$, the $\theta$ value was noticed as $0.125 \mathrm{~cm}^{3} \mathrm{~cm}^{-3}$ for fresh water against the actual value of $0.16 \mathrm{~cm}^{3} \mathrm{~cm}^{-3}$ for $3.83 \mathrm{dS} \mathrm{m}$ which was exceeded by $0.035 \mathrm{~cm}^{3}$ $\mathrm{cm}^{-3}$. The capacitance AG probe showed $\theta$ value as $0.145 \mathrm{~cm}^{3} \mathrm{~cm}^{-3}$ for $3.83 \mathrm{dS} \mathrm{m}^{-1}$ whereas the value for fresh water was $0.165 \mathrm{~cm}^{3} \mathrm{~cm}^{-3}$ indicating an overestimation of $0.02 \mathrm{~cm}^{3} \mathrm{~cm}^{-3}$.

Studying the calibration data of P1 probe in Fig. 2, we found that at $0.2 \mathrm{~V}$, the $\theta$ value was recorded as 0.18 $\mathrm{cm}^{3} \mathrm{~cm}^{-3}$ for fresh water i. e., an overestimation of 0.04 as compared to $3.83 \mathrm{dS} \mathrm{m}^{-1}\left(\theta=0.14 \mathrm{~cm}^{3} \mathrm{~cm}^{-3}\right)$. For P2 at voltage 0.56 , the $\theta$ was measured as $0.17 \mathrm{~cm}^{3} \mathrm{~cm}^{-3}$ for fresh water and $0.16 \mathrm{~cm}^{3} \mathrm{~cm}^{-3}$ for soil solution of $3.83 \mathrm{dS} \mathrm{m}^{-1}$.

These results indicated that the dielectric moisture probes overestimated $\theta$ when the $\mathrm{EC}_{\mathrm{w}}$ was apparently high. At the salt concentration of $9.15 \mathrm{dS} \mathrm{m}^{-1}$, the tested ML1, ML2 and SK8 probes differed for $\theta$ measurement by $0.01-0.03 \mathrm{~cm}^{3} \mathrm{~cm}^{-3}$ as compared to fresh water treatment (Table 2). For MP4, MIN, SM2 and P2, the $\theta$ measurement difference was recorded up to $0.05 \mathrm{~cm}^{3}$ $\mathrm{cm}^{-3}$ when comparing with fresh water. Among the sensors, WET, EC2, P1, AG and ES were ranked as the sensitive sensors due to the $\theta$ difference of more than $0.06 \mathrm{~cm}^{3} \mathrm{~cm}^{-3}$ at EC level of $9.15 \mathrm{dS} \mathrm{m}^{-1}$.

\section{CONCLUSIONS}

The effects of $\mathrm{EC}_{\mathrm{w}}$ on the measurement of $\theta$ indicated that all the commercially available moisture probes overestimated the $\theta$ when the $\mathrm{EC}_{\mathrm{w}}$ was very high. Our results showed that ES, AG and P1 sensors over estimated the volumetric water content by approximately $0.02-0.04 \mathrm{~cm}^{3} \mathrm{~cm}^{-3}$ when the salt concentration was $3.83 \mathrm{dS} \mathrm{m}^{-1}$. With higher EC value, a larger error was noticed. For agricultural purpose, it could be necessary to use a sensor that may be resistant to the salt concentration up to $4 \mathrm{dS} \mathrm{m} \mathrm{m}^{-1}$. Thus among the commercially available moisture meters, ML1, ML2, SK8 and P2 provided higher accurate readings when $\mathrm{EC}_{\mathrm{w}}$ value was $3.83 \mathrm{dS} \mathrm{m} \mathrm{m}^{-1}$. The low-priced EC2 sensor was found highly susceptible to salts among all types of sensors tested. Low output accuracy was observed for SK8 probe when the $\mathrm{EC}_{\mathrm{w}}$ was higher and the $\theta$ was lower. The modified SK8 sensor output displayed sufficient accuracy up to the range of $17.7 \mathrm{dS} \mathrm{m}^{-1}$ for the simultaneous measurement of $\theta$ and $\mathrm{EC}_{\mathrm{w}}$ in a saline sandy soil. Thus modifying configuration of the sensor may mitigate the effects of salts on sensor output values. Testing dielectric moisture probes under various climatic and soils conditions in the field would be the subject of our future studies.

\section{ACKNOWLEDMENT}

The authors gratefully thank the financial support by Global COE program of Japan Society for Promotion of Science.

\section{REFERENCES}

1. Amato, M. and J.T. Ritchie, 1995. Small spatial scale soil water content measurement with timedomain reflectometry. Soil Sci. Soc. Am. J., 59: 325-329.

2. Baker, J.M. and R.R. Allmarasm, 1990. System for automating and multiplexing soil moisture measurement by time-domain reflectometry. Soil Sci. Soc. Am. J., 54: 1-6.

3. Campbell, J.E., 2002. Salinity effects in capacitive soil moisture measurement. Pap. No. 1.2. In I. C. Paltineau (Ed.) Trans. Int. Symp. on Soil Water Measurement Using Capacitance and Impedance, 1st, Beltsville, MD. 5-7 Nov. 2002. PALTIN Int., Laurel, MD. 
4. Dean, T.J., 1994. The IH capacitance probe for measurement of soil water content. Rep. 125. Inst. of Hydrol., Wallingford, UK.

5. Dean, T.J., J.P. Bell and A.J.B. Baty, 1987. Soil moisture measurement by an improved capacitance technique: Part I. Sensor design and performance. J. Hydrol., 93: 67-78.

6. Dalton, F.N. and M.Th. van Genuchten, 1986. The time-domain reflectometry method for measuring soil water content and salinity. Geoderma, 38: 237-250.

7. Dalton, F.N., W.N. Herkelrath, D.S. Rawlins and J.D. Rhoades, 1984. Time-domain reflectometry: simultaneous measurement of soil water content and electrical conductivity with a single probe. Science, 224: 989-990.

8. Dehghanisanji, H., T. Yamamoto and M. Inoue, 2004. Practical aspects of TDR for simultaneous measurements of water and solute in a dune sand field. J. Jpn. Soc. Soil Phys., 98: 21-30.

9. Dobson, M.C., F.T. Ulably, M.T. Hallikainen and M.A. El-Rayes, 1985. Microwave dielectric behaviour of wet soil, II, Dielectric mixing models, IEEE Trans. Geosci. Remote Sens, 23: 35-46.

10. Evett, S.R. and J.L. Steiner, 1995. Precision of neutron scattering and capacitance type soil water content gauges from field calibration. Soil Sci. Soc. Am. J., 59: 961-968.

11. Heimovaara, T.J. and W. Bouten, 1990. A computer-controlled 36-channel time domain reflectometry system for monitoring soil water contents. Water Resour. Res., 26: 2311-2316.

12. Herkelrath, W.N., S.P. Hamburg and F. Murphy, 1991. Automatic, real-time monitoring of soil moisture in a remote field area with time-domain reflectometry. Water Resour. Res., 27: 857-864.

13. Inoue, M., 2005. Assessment and modification to select dielectric moisture probes for simultaneous measurement of soil water and salinity, Proceedings of International Workshop on Research Progress and Current Issue of Unsaturation, Processes in Vadose Zone 59-62.

14. Jones, S.B., J.M. Wraith and D. Or, 2002. Time domain reflectometry measurement principle and applications. Hydrol. Process, 16: 141-153.

15. Kelleners T.J., D.A. Robinson, P.J. Shouse, J.E. Ayars and T.H. Skaggs, 2005. Frequency dependence of the complex permittivity and its impact on dielectric sensor calibration in soils. Soil. Sci. Soc. Am. J., 69: 67-76.

16. Kelleners T.J., R.W.O. Soppe, J.E. Ayars and T.H. Skaggs, 2004. Calibration of capacitance probe sensors in a saline silty clay soil. Soil. Sci. Soc. Am. J., 68: 770-778.

17. Mwale, S.S., S.N. Azam-Ali and D.L. Sparkes, 2005. Can the PR1 replace the neutron probe for routine soil-water measurement? Soil Use Manage, 21: 340-347.
18. Or, D. and J.M. Wraith, 1999. Temperature effects on soil bulk dielectric permittivity measured by time domain reflectometry: A physical model. Water Resour. Res., 35: 371-383.

19. Paltineanu, I.C. and J.L. Starr, 1997. Real-time soil water dynamics using multisensor capacitance probes: Laboratory calibration. Soil Sci. Soc. Am. J., 61: 1576-1585.

20. Regalado, C.M., A. Ritter and G.R.M. Roddriguez, 2007. Performance of the commercial WET capacitance sensor as compared with Time Domain Reflectometry in Volcanic soils. Vadose Zone J., 6 (2): 244-254.

21. Risler, P.D., J.M. Wraith and H.M. Jaber, 1996. Solute transport under transient flow conditions estimated using time domain reflectometry. Soil Sci. Soc. Am. J., 60: 1297-1305.

22. Robinson, D.A., C.M.K. Gardner, J.D. Cooper, M.G. Hodnett and J.P. Bell, 1998. The dielectric calibration of capacitance probes for soil hydrology using an oscillation frequency response model. Hydrol. Earth System Sci., 2: 111-120.

23. Roth, K., R. Schulin, H. Fluehler and W. Attinger, 1990. Calibration of time-domain reflectometry for water content measurements using a composite dielectric approach. Water Resour. Res., 26: 2267-2273.

24. Seyfried, M.S. and M.D. Murdock, 2004. Measurement of soil water content with a $50-\mathrm{MHz}$ soil dielectric sensor. Soil Sci. Soc. Am. J., 68: 394-403.

25. Speer, M., A. Brune and W.M. Kaiser, 1994. Replacement of nitrate by ammonium as the nitrogen sources increases the salt sensitivity of pea plants. I. Ion concentrations in roots and leaves. Plant Cell Environ., 17: 1215-1221.

26. Topp, G.C. and J.L. Davis, 1985. Measurement of soil water content using time-domain Reflectometry (TDR): A field evaluation, Soil Sci. Soc. Am. J., 49: 19-24.

27. Topp, G.C., J.L. Davis and A.P. Annan, 1980. Electromagnetic determination of soil water content: Measurements of coaxial transmission lines. Water Resour. Res., 16: 574-582.

28. Topp, G.C., S. Zegelin and I. White, 2000. Impact of real and imaginary components of relatively permittivity on time domain reflectometry measurement in soils. Soil Sci. Soc. Am. J., 64: 1244-1252.

29. Wraith, J.M. and D. Or, 1999. Temperature effects on soil bulk dielectric permittivity measured by time domain reflectometry: Experimental evidence and hypothesis development. Water Resour. Res., 35: 361-369. 